\title{
Tobacco policies and vulnerable girls and women: toward a framework for gender sensitive policy development
}

\author{
Lorraine Greaves, Natasha Jategaonkar
}

J Epidemiol Community Health 2006;60(Suppl II):ii57-ii65. doi: 10.1136/jech.2005.045393

This article assesses the effects of comprehensive tobacco control policies on diverse subpopulations of girls and women who are at increased vulnerability to tobacco use because of disadvantage. The authors report on a recent assessment of experimental literature examining tobacco taxation; smoking location restrictions in public and private spaces; and sales restrictions. A comprehensive search was undertaken to identify relevant studies and evaluation reports. Gender based and diversity analyses were performed to identify pertinent sex differences and gender influences that would affect the application and impact of the policy. Finally, the results were contextualised within the wider literature on women's tobacco use and women's health. The authors consider not only the intended policy effects, but also explicitly examine the gendered and/or unintended consequences of these policies on other aspects of girls and women's health and wellbeing. A framework for developing gender sensitive tobacco programmes and policies for low income girls and women is provided.

See end of article for authors' affiliations

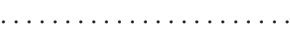

Correspondence to: Dr L Greaves, British Columbia Centre of Excellence for Women's Health, Vancouver, BC, Canada; lgreaves@cw.bc. $\mathrm{ca}$

Accepted for publication 20 June 2006
D eveloped countries such as the USA and Canada have been successful in reducing the use of tobacco across their populations by about $50 \%$ in the past 40 years. ${ }^{1-3}$ However, these reductions have usually taken place first among the economically and socially advantaged, and the rate of decline in smoking among men has been more rapid than women in most developed countries. ${ }^{4}$

Specific sub-populations are now exhibiting trends that require even more nuanced analyses. Smokers are now a minority of the population in many developed countries, and are generally disadvantaged or occupy marginal positions in their societies. These groups may be poor, of particular minority groups, Aboriginal, young, and/or in specific occupations or situations, such as experiencing violence or mental illness. Indeed, indigenous people are displaying rates of smoking often double the average of the broader population. ${ }^{5-8}$ These patterns have emerged in the context of comprehensive tobacco policy environments. For example, low income people in developed countries are now most likely to start and maintain tobacco use despite increasing taxes and prices and widespread public health messaging and health knowledge about the dangers of smoking.
Gender, a key determinant of health, acts in concert with these elements of disadvantage or identity, and has become an important dimension for researchers to explore in understanding the psychosocial and economic underpinnings of women's smoking in the 21 st century. For example, although males have historically smoked at higher rates than females in every age group, in the past two decades, teen girls have begun to smoke more than teen boys in several industrialised countries. ${ }^{9}$ Women are also exposed to others' smoking. Passive or involuntary smoking in the households or workplace is affected by sex specific vulnerabilities and gender issues*. Health consequences for women and their children from such exposures include increased cancer, ${ }^{10}{ }^{11}$ chronic obstructive pulmonary disease, ${ }^{12}$ and asthma. ${ }^{13}$ For pregnant women, increased risks affect the health of both the woman and the fetus. ${ }^{14-16}$ Gender issues include increased female or household poverty when males take up smoking that may lead to compromised family nutrition. However, resolving such issues can be complex. As Ernster et al ${ }^{17}$ point out "empowering women to limit exposure to environmental tobacco smoke (ETS) in their homes is a challenge to public health policymakers because it addresses gender inequality in the private sphere."

\section{POLICY APPROACHES}

The tobacco control movement has developed and assessed numerous approaches to curbing the tobacco epidemic and reducing or eliminating the use of tobacco over the past 50 years. The main conclusion is that a comprehensive approach is most effective in reducing tobacco use prevalence rates of the population, which has led to comprehensive tobacco policies (CTPs) being established in many jurisdictions. These approaches include a range of policies, such as those dealing with tax and price, restrictions on smoking locations, sales to minors, advertising and marketing enforcement, community programmes, and surveillance. ${ }^{18} 19$ CTPs have led to considerable decline in the prevalence of smoking in some populations. ${ }^{20-22}$ In some jurisdictions "denormalisation" has been added as a component of a CTP (for example, Non-Smokers'

* Sex refers to the biological characteristics that generally differentiate between females and males. Gender refers to the socially constructed factors and roles that affect or are attributed to women or men.

Abbreviations: SES, socioeconomic status; CTP comprehensive tobacco policy; BP, best practice; GBA, gender based analysis 
Rights Association in the United States, National Strategy to Reduce Tobacco Use in Canada), transforming smoking into an increasingly socially unacceptable activity. Social marketing and health promotion campaigns on both prevention and cessation usually complement this menu.

\section{WHY STUDY THE EFFECTS OF TOBACCO POLICY ON LOW SOCIOECONOMIC STATUS (SES) GIRLS AND WOMEN?}

This article assesses how tobacco policies affect low SES girls and women, who may also experience other vulnerabilities. This question is critically important if countries wish to continue to lower their rates of smoking. Understanding both the realities of disadvantage among girls and women, as well as the effects of CTPs, and how these factors interact is crucial to reducing or eliminating the use of tobacco among disadvantaged girls and women.

SES is an indicator of location within the social and economic hierarchy, and is composed of measures of income, education, and occupation. A vulnerable population is one that experiences social and economic conditions that contribute to or indicate risk of poor health. With respect to tobacco use, vulnerable groups are those whose life circumstances or group membership(s) reflect inequities or norms that make them more likely to use tobacco and less likely to quit once they do.

Health equities and inequities constitute a strong thread in any discussion about vulnerability to tobacco use. Income adequacy and access to material resources, or its counterpart, experiences of material deprivation, contribute to smoking initiation and cessation during both adolescence and adulthood. It has been shown in 12 European countries that income level has an effect on smoking prevalence, independent of education. ${ }^{23}$ Early life experiences that are characterised by poverty and low education influence later SES, and both influence smoking patterns. ${ }^{23}$ For women in particular, Graham and Der have identified several life paths that coincide to affect smoking rates in low income girls and women. ${ }^{24}$

Access to and distribution of material resources reflect political processes and economies and raise issues of whether or not people and groups have equal opportunity to access health services and more pertinently, how they experience the effects of the determinants of health..$^{25}$ Gender equity in health is related, in that it highlights issues such as the distribution of material resources and opportunities to girls and women compared with boys and men. Although all of these inequities reflect structural problems, resolving gender inequity will require the elimination of "unnecessary, avoidable and unjust inequities which exist as a result of the social construction of gender" (pagel). ${ }^{26}$

\section{BACKGROUND}

The sex and gender specific issues related to women's tobacco use have been studied for less than 25 years. Up until the 1980s, attention paid to "women and tobacco" generally focused narrowly on pregnancy, reproduction, and smoking. ${ }^{27-29}$ Comprehensive consideration of the myriad of issues connected to women's health, socioeconomic conditions and tobacco use is a comparatively recent phenomenon. At the same time, the tobacco industry has vigorously targeted girls and women since the $1920 \mathrm{~s},{ }^{29}{ }^{30}$ and working class and (comparatively) disadvantaged girls and women since the 1980s. ${ }^{31}$ None the less, in the past 25 years considerable evidence has accumulated on sex differences in the effects of tobacco on girls and women, and gender influences on tobacco related behaviours such as initiation, maintenance, and cessation. ${ }^{32}{ }^{33}$ These findings point to the need for continued sex differentiated and gendered research and analysis of all aspects of tobacco use, including the responses to tobacco policies.

\section{Some examples of rates and trends}

Evidence is growing about the influence of sex, gender, and diversity on tobacco use in several developed countries. Epidemiological data show that smoking follows a class gradient of health in the USA and most developed countries. ${ }^{31}$ (However, national surveillance systems are not always able to describe co-occurring or multiple aspects of disadvantaged smokers' experiences. Rather, reliance on small surveys, cross sectional studies, or community based research is necessary to fill out the picture.

For example in Canada, at the lowest income level, smoking prevalence among women was about 35\%, and $41 \%$ among men in 1996-97. In contrast, smoking prevalence at the highest income level was $18 \%$ for women and $22 \%$ for men. ${ }^{34}$ In the USA, SES and level of education have been shown to be strong predictors of tobacco use. Among the students graduating from high school in 1999, those with no plans to attend a four year college programme were 1.45 times more likely to smoke than their college attending counterparts (University of Michigan, 1999, cited in Barbeau et al). ${ }^{31}$

The rate of cigarette smoking among Aboriginal people in Canada is about twice the rate of cigarette smoking in nonAboriginal people and rises to about $70 \%$ in some segments of the Aboriginal population. ${ }^{6}$ Unlike the prevalence among the non-Aboriginal populations, rates among Aboriginal populations in both the USA and Canada are not declining. ${ }^{35-37}$ Aboriginal men tend to report a higher daily consumption of cigarettes than Aboriginal women; however, Aboriginal women are more likely than Aboriginal men to have begun smoking between 9 and 11 years of age. ${ }^{38}$

A recent nationwide study has investigated the influence of sexual orientation on adolescent smoking rates in adolescents in the USA. The researchers found that girls who identified themselves as being lesbian or bisexual were 10 times more likely to have smoked at least weekly in the past year compared with their heterosexual counterparts. ${ }^{39}$ Lesbian and bisexual girls were also almost five times more likely to report that most or all of their friends smoked tobacco. ${ }^{39}$ Conversely, homosexual or bisexual boys scored 1.5 points lower than their heterosexual counterparts on the index of tobacco dependence. ${ }^{39}$ This again suggests the significance of gender based study of marginalised populations with regard to tobacco use.

\section{Complexity of cross-issues}

Amplifying on these national trends, evidence is increasing that various experiences associated with disadvantage, low SES, or minority group status contribute to the picture of understanding tobacco use. Research data on these multioccurring situations are incomplete but increasing. Although some vulnerable groups, such as victims of violence or lone parents are overwhelmingly female, a sex and gendered analysis of these multi-occurring issues is generally absent. Women who are single parents, ${ }^{40}{ }^{41}$ and persons who have survived sexual and physical abuse, ${ }^{42}$ are more likely to smoke.

European research shows that multiple disadvantages accumulate to influence both smoking initiation and cessation. $^{23}$ In Britain, four SES factors were independent predictors of smoking, and prevalence among women who experienced all four was $73 \%$, compared with $46 \%$ among women who experienced only one. ${ }^{43}$ In Germany, for example, quit rates were lowest for groups experiencing low education, limited income, and low labour force participation concurrently. ${ }^{44}$ 
Both biological and social factors interplay to create vulnerability. For example, children of women who smoked while pregnant are more likely to become smokers because of biological predispositions established during fetal development. ${ }^{45} 46$ Additionally, children whose mothers smoke also are more likely to smoke because of the effects of role modelling. ${ }^{47}{ }^{48}$ Applying a full gender analysis requires that these cross-issues, both biological and psychosocial, are taken into account. These diversities of experience clearly affect initiation, maintenance, and cessation of smoking, as well as create differential responses to tobacco interventions and policies.

\section{METHODS}

This article relied on a multi-stage analysis of available evidence to assess the impact of tobacco control policies on vulnerable groups of girls and women. A comprehensive review of existing empirical literature was conducted to examine the efficacy and effectiveness of three important aspects of tobacco control policy (price and taxation, smoking location restrictions, and sales restrictions) on three key populations of interest (Aboriginal peoples, youth, people living on low income). Full details of the methods and results of this report can be found elsewhere. ${ }^{49}{ }^{50}$ The results that particularly pertain to women and girls of low SES were extracted from this report for separate secondary analysis and consideration. Finally, a framework for gender sensitive tobacco policy was developed using these findings, augmented by additional literature reviews that form the basis for contextualising these data and forming recommendations.

In the initial comprehensive review, evidence was collected from a variety of sources, including key word searches $\dagger$ on library and online databases (for example, PubMed, PsycInfo, World Health Organisation, Social Work Abstract, Women's Studies International), publications by provincial and federal governments and non-government organisations, and sources identified by key contacts in the tobacco control movement. Citation chasing was also used as a strategy to identify pertinent reports. Efforts were made to identify evaluations carried out in countries where CTPs are in place (for example, USA, Canada, UK, Australia, New Zealand) although evidence from all countries was considered.

To be considered in the review, the study or report was required to be published (or conducted, if unpublished) between 1990 and 2003 and designed to explore the impact of price and taxation or sales restrictions, or location restrictions (or two or more of these policies). The study was required to have included a sample of adolescents, Aboriginal people, people living on low income, or the general population. In addition, the study was required to include measurement of at least one of the following outcomes of interest: tobacco use related to incidence of initiation or cessation; prevalence of smoking; prevalence of tobacco sales; number of quit attempts; intent to quit; and stage of change.

A better practices (BP) methodology designed by tobacco control researchers was used to assess both the efficacy and effectiveness of each of the policies under study. The BP model ${ }^{51}{ }^{52}$ has previously been applied to smoking cessation among specific sub-populations, such as teenagers, ${ }^{53}$ and pregnant women. ${ }^{54} \mathrm{BP}$ methodology is a form of systematic review of qualitative and quantitative evidence that considers both the strength and the quality of evidence. Specific criteria

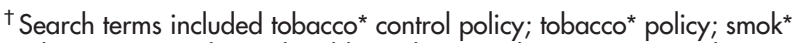
and women; smok* and public policy; smoking \& tax; smoking \& aboriginal; health policy and tobacco; tobacco and income; tobacco and adolescents; smok ${ }^{*}$ and income; smok ${ }^{*}$ and adolescents; smok ${ }^{*}$ and aboriginal; government policy \& tobacco*; smoking laws and regulations are applied to existing literature with the aim of producing useful recommendations for appropriate approaches in reducing morbidity and mortality related to tobacco use.

Once the experimental literature was collected, rating its strength involved a multi-step process. All of the evidence was rated by two independent reviewers using a rating system adapted for this review (based on the work of Miller et al). ${ }^{55}$ Once rated, each study was further classified as high, medium, or low level of strength, and several plausibility criteria were applied: Was the evidence replicable? Could the results be generalised? Is the intervention cost effective? Can it be evaluated?

In the next stage of this project, a gender based analysis (GBA) and diversity analysis of the findings was conducted. The purpose of the gender based and diversity analyses was to assess biases related to gender and diversity that exist when developing research questions, literature reviews, research designs, methods and data gathering techniques, data analyses and interpretation, language, and visual representations. The methodology used to conduct these analyses is outlined in a Health Canada report entitled, Exploring Concepts of Gender and Health..$^{56}$ Finally, findings from all stages of the review were synthesised and contextualised within broader literatures to provide final recommendations.

Specific information relevant to women and girls was later extracted from this review, and considered in the context of broader literature searches to augment the discussion and work toward development of a framework for gender sensitive tobacco policy development. The contextual literature included consideration of broader topics such as diversity, gender and health, women's health, woman centred care, and aspects of tobacco programming and policy. Both intended and unintended consequences for each policy were considered, and unanswered questions regarding these effects were identified. The framework presented in this article arises from the results of these three phases of research.

\section{RESULTS}

\section{Overview}

In searching for experimental literature that addressed the impact of tobacco control policy on vulnerable groups, more than 70 articles were identified. However, most of these used a general population of participants as its sample; very few considered gender, age, or income specific policy impacts, reflecting a dearth of research on the questions of interest. Twenty four studies assessed the impact of sales restrictions policies, such as minimum age of sales and merchant compliance; 18 studies examined the influence of price and taxation on tobacco products; and 30 studies were identified that considered smoking location restrictions in workplaces, schools, and homes. Despite this lack of attention, results reflecting the differential impact of tobacco control policy on girls and women were extracted where possible.

\section{Sales restrictions}

The experimental literature showed that the likelihood of a successful tobacco purchase varies by gender. Girls are less likely to attempt to purchase cigarettes, ${ }^{58}$ but are more likely than boys to be acquiring cigarettes from non-commercial sources. ${ }^{59}$ Among teens who do attempt to purchase cigarettes, girls are more likely to be successful. ${ }^{60}$ Interestingly, both the gender of the teenager and the gender of the merchant may play a part in whether or not a purchase attempt is successful. One study found that female clerks are less likely to sell cigarettes to minors than are male clerks. ${ }^{60}$

The study by Klonoff $e t a l^{60}$ shows that the effectiveness of sales restrictions also may vary by ethnicity. For example, the 
researchers fouund that Latino teenagers (age 10-16 years) were significantly more likely to successfully purchase cigarettes compared with white teenagers of the same age range. However, Latina girls were successful on $28 \%$ of their purchase attempts, and Latino boys were successful on only $6 \%$ of attempts. Anecdotal evidence in Canada has suggested that South Asian girls may use their success in acquiring cigarettes as a means to gain peer respect or popularity by purchasing cigarettes for others (A Dauphinee, personal communication, 30 November 2004). Aboriginal girls may also have higher success in obtaining cigarettes, as exempt sale retail dealers on Canadian reservations present another source of cigarettes in addition to stores, friends, and family.$^{61}$

\section{Price and taxation}

Chaloupka and Pacula ${ }^{62}$ examined cross sectional data from American high school students and found that the taxation of tobacco products was less likely to result in a decrease in smoking prevalence among girls than among boys. Lewit et $a l^{63}$ have also reported similar findings. Consistent with the research carried out among adult smokers, Biener et al ${ }^{64}$ have found that adolescent smokers from low income households are also highly responsive to price increases as compared with teens from higher income households.

Further research is needed to understand the effects of price and taxation of tobacco products on Aboriginal peoples in the USA and Canada. These communities are rarely examined in tobacco policy research, and thus it is difficult to determine their price responsiveness. People living on reservations or reserves are generally purchasing cigarettes from exempt sale retail dealer merchants, and thus any change in taxation is unlikely to have an effect on the Aboriginal women and girls who live there.

\section{Location restrictions}

The studies carried out to date suggest that workplace smoking restrictions have a moderate effect in decreasing smoking prevalence and cigarette consumption and that partial bans are less effective than complete smoking restrictions. Although gender and SES are each considered in a small number of evaluations, it is rare that both variables are considered concurrently within one study. Two studies in our review considered gender differences in the response to workplace smoking restrictions among smokers living on low income. ${ }^{65}{ }^{66} \mathrm{Gritz}$ et $a l^{65}$ carried out a study to evaluate the impact of a 2.5 year workplace health promotion intervention, which included posters, interactive events, and individual self assessments in addition to smoking restriction policies being implemented at the worksite. Among those who received the intervention, women were more likely than men to report smoking fewer cigarettes per day but also reported fewer quit attempts. No difference was seen in the proportion of women and men in the intervention group who were able to successfully quit smoking, although women in the intervention group were more likely to successfully quit than women in the control group. In their assessment of workplace smoking restrictions among several industry groups in the USA, Farrelly et $a l^{66}$ found that workplace bans were less likely to influence women's smoking prevalence as compared with men's.

As with workplace restrictions, persons or families may choose to ban smoking in their homes to protect nonsmokers from secondhand smoke and/or to encourage cessation among those who do smoke. Adolescents who live in homes where smoking is restricted or not permitted at all for adult smokers are less likely to experiment with cigarette smoking, ${ }^{67}$ or are less likely to transition to a later stage of smoking uptake. ${ }^{68}$ In the only study identified that examined gender differences among adolescents, Proescholdbell et al ${ }^{67}$ report that permissive home smoking policies are more strongly related to regular smoking for girls than for boys.

Unintended consequences and unanswered questions Existing evidence suggests that each of these policies shows some effect in reducing overall smoking prevalence, the intended outcome. However, it is also important from a health and social justice point of view to consider any unintended consequences of these policies as well. Little research addresses this aspect explicitly, and thus much of the following discussion about unintended consequences is speculative and points to areas for further study.

Sales restrictions, while sending a strong message about the social acceptability of smoking for youth, do not prevent girls and boys from acquiring cigarettes. Even when strictly enforced, teens, especially girls, who smoke may bypass sales restrictions by turning to other sources to obtain cigarettes. Friends and family members often provide cigarettes to underage smokers. The recent advent of internet tobacco sales may also facilitate access to cigarettes for adolescents, although it is not clear whether gender differences exist.

Increased taxation of tobacco products is effective in reducing smoking prevalence, but this policy practice raises ethical question when considering low SES girls and women. Debate is ongoing about whether or not increased tobacco taxes are progressive or regressive. ${ }^{69-71}$ Given that lower income groups in the USA, Canada, and other developed nations have a high prevalence of smoking, tobacco taxes inevitably place a higher burden on people who may already be struggling to make ends meet. In the absence of accessible and effective smoking cessation programmes, it is worth asking whether it is fair for people living on low income to be paying a disproportionate share of tobacco taxes.

In the case of UK low income mothers, both absolute and relative spending on tobacco is higher than in high income households. ${ }^{72}$ In addition, qualitative data show that these mothers considered tobacco an essential expenditure compared with food..$^{72}$ In short, cigarette smoking presents a critical economic problem for low income women. As ASH points out, "although ....an individual luxury item, spending on tobacco had the hallmarks of a collective necessity" (page 28). ${ }^{72}$ In Canada, Hamilton examined the effects of tax changes on poor smokers between 1978 and 1994 and found that there was a "direct negative correlation between smoking expenditures and purchases of essential items such as food, clothing, shelter, and health-care" (page 1). ${ }^{73}$

Restrictions on the locations where smoking is permitted or not permitted have sometimes contributed to the increased visibility of smokers, as they move outside or into public spaces. In the context of "denormalisation" this visibility can lead to increasing the stigma associated with smoking. The resultant divide between smokers and non-smokers may have other negative consequences, contributing to discriminatory practices and social stereotyping. ${ }^{74}$ They also may conflict with the policy goal of deterring smoking, because research on adolescents suggests that smokers whose peer group is entirely made up of smokers will have a harder time quitting successfully. ${ }^{75}{ }^{76}$ Indeed, Alesci et a l7 $^{77}$ suggest that the high visibility of smoking encourages its social acceptability and that youth may be more likely to smoke as a result. It is not clear how (or if) this experience may differ for girls than for boys.

The differential impact of home smoking bans on adult women and men is rarely examined in the research literature. However, in their 2000 report entitled Filtered Policy, Greaves and Barr $^{78}$ illustrate how women's roles tend to make both the implementation and the experience of home smoking restrictions different for women than for men. Firstly, even when wanting to protect the health of non-smokers in the 
home (particularly children), women may not have control over their families' home air space, especially when a male partner is a smoker. Secondly, it is important to recognise that "it is mothers, not fathers, who spend the most time with young children in the home" (page 37), ${ }^{78}$ and thus the expectation is for women's smoking behaviour to change.

Women's role as primary caregiver and nurturer enhances the impact of ETS policies, particularly those directed at improving fetal or child health. In microsocial qualitative research examining the impact of smoking policies on pregnant and postpartum women in their family context, Bottorff and colleagues conclude that these women are faced with "compelled tobacco reduction" ${ }^{79}$ This pressure is a clear example of the impact of sex and gender on the lived experience of comprehensive tobacco policies. In addition, the couple dynamics created by this pressure were complex, ranging from disengaged to accommodating to conflictual. ${ }^{79}$ Pregnant women who did not reduce smoking, or alternatively, lived with partners who did not reduce smoking were faced with increased social pressures and complexities in their relationships. Some of the women reported being pressured, ridiculed, or controlled by their partner with respect to their smoking, offering insight into micro experiences of tobacco control policy.

Aboriginal women may experience additional issues in responding to smoking location restrictions and ETS policies. They may have greater difficulty in trying to maintain smoke free homes for themselves and their families, as housing shortages on many reserves and reservations (and in many urban communities) may mean sharing accommodation with relatives or friends and thus having less control over the rules of the home.

\section{DISCUSSION}

It is time to address the potential for a more nuanced and sensitive tobacco policy approach for low SES girls and women. Although women specific and sensitive tobacco programming and prevention has been supported in some countries, there has been less action in the policy arena. INWAT Europe called for a broad gender sensitive policy development process in 1999 to address women's smoking. ${ }^{80}$ European writers have also recently questioned whether or not tobacco policies, even if improved, will succeed in reducing the inequalities of smoking without adopting a distinct equity focus (page 42). ${ }^{23}$

The meaning of smoking and its links to identity, image, risk and dependencies among women have been established. ${ }^{29}$ Reflecting and rectifying the differences in tobacco use means that it will be necessary to address the underlying issues connected to tobacco use disparities, at both the individual and social levels and respond with modified social and economic policies. This approach is to be distinguished from simply increasing pressure on girls' and women's smoking behaviours by tailoring programme and prevention approaches. Rather, it implies that CTPs should also include a range of other policies that address social and health inequities.

Assessing and measuring the impact of tobacco policy is complicated by multiple policy initiatives taking place simultaneously. ${ }^{81}$ In examining the available data, it is difficult to draw out the precise effects of each policy on girls and women among various sub-populations, or more specifically low SES girls and women. Furthermore, disentangling the effects of each policy approach on girls and women, in the context of a comprehensive approach is difficult. Assessing the precise impact of each of these in the context of other social and legal changes, such as trends toward denormalisation, changes in exposure to or type of advertising imagery from tobacco companies, or legal

\section{What this paper adds}

This paper examines the literature girls, women, gender, and tobacco policies to identify any gendered, differential effects, or unintended consequences on various vulnerable groups. The results are placed in context of wider literature on women's health. Little research asking these questions exists, and little reflection has taken place on the links between tobacco and wider social and health policies that affect vulnerable girls and women. A framework for developing and improving tobacco policies is suggested.

challenges to various aspects of tobacco policy and enforcement is an additional challenge. Although we assume that synergistic effects occur between policies, ${ }^{82}$ it is difficult to identify their nature and scope and then apply that knowledge to girls and women, especially those of low SES.

Despite the gendered nature of the clustering of tobacco use among vulnerable and disadvantaged people, it seems that little research attention has focused on gender differences. $^{.00}$ Additionally, little direct research has been conducted on the impacts of each of the three policy areas on girls and women with the exception of youth, who have been the subject of considerable research on tobacco programme and policy implementation. However, much of the literature on youth does not distinguish by SES. ${ }^{50}$ Little clear evidence is available that shows the differential effects of tobacco policies on vulnerable populations in general, or on low SES girls and women in particular. None the less, when available data are contextualised in other literatures and then undergo GBA and diversity analysis ramifications and potential unintended consequences emerge. Although such conclusions do not diminish the broad based population health effects of tobacco policies, they point to the importance of asking questions to further research on the effects of tobacco policy.

Kenneth Warner made this point in 2001, when examining research on the effects of taxation, which he claimed were less well understood than previously thought. ${ }^{83}$ He states that novel findings (such as youth switching to higher tar brands in face of higher prices):

\section{"highlight the importance of contemplating the nuances of policy consequences, and they demonstrate the value of pursuing thoughtful, creative research even on the most well-established interventions."}

Warner went on to say:

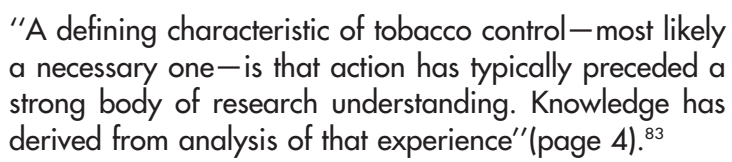

This iterative process can continue to be used in tobacco policy development and analysis to further refine the field and extend its progress. However, this process should be tempered and improved with a sex, gender, and diversity based analysis. In addition, the notion of unintended consequences is a concept that needs to be embraced by analysts, to begin the process of tailoring our policy responses to low SES girls and women and other disadvantaged groups.

Current tobacco policies reflect little or no differentiation by sex and gender. Although sex disaggregated trend and prevalence data are now routinely collected and disseminated 
by many developed countries (for example, CTUMS, Statistics Canada, CDC, NHS Scotland, ASH), only limited GBA is applied to most tobacco policies. Indeed, the situation regarding GBA differs country by country.

In Canada, for example, a GBA policy was adopted by the federal government in 1995 under the Federal Plan for Gender Equality, ${ }^{84}$ and the specific GBA policy adopted by Health Canada in 1999 as part of Canada's Women's Health Strategy. ${ }^{85}$ Since then, specific manuals have been published, directing policy makers on how to apply a GBA. ${ }^{86}$ With respect to non-governmental research and evaluation, no broad recommendation to apply sex and gender based analyses to tobacco research, programmes, and policies existed until the publication of the report on the Canadian Tobacco Control Research Summit in 2002. ${ }^{87}$ Now, this recommendation applies to all tobacco researchers as they make proposals for funding to federal agencies.

Although the USA has no general GBA policy for government that would improve policy development in itself, researchers seeking funding are required to account for the inclusion of women, minors, and minorities in their proposed research. This provision was established in 1993, and by 1999 had achieved a 95\% compliance rate. However, the rates of analysis of these sex and gender related data were much lower, showing a lack of use of some very valuable information. ${ }^{88}$ Whether or not these data were illuminating regarding sex and gender differences in tobacco use or responses to policy, is not known.

\section{WHAT WOULD AN ETHICAL FRAMEWORK FOR TOBACCO POLICY LOOK LIKE?}

"The construct of social justice can help counteract disparities in current tobacco control measures as well. Along the way, public health practitioners may find themselves moving beyond the better health business into the realm of social justice" (page 1860)..$^{89}$

We propose a framework that entails policy, research, and programme development and that reflects social justice and human rights principles. Discussions about ethical approaches to implementing research, programmes, and policies in health are ongoing, particularly with respect to vulnerable populations. ${ }^{90}$ In general, an ethical approach implies doing no harm, causing benefit for the group in the long run, and obtaining fully informed (individual and group) consent regarding risk..$^{90}{ }^{91}$ Wilson and Thomson suggest an ethical approach to tobacco taxation requires consideration of harms and benefits as well as the autonomy of low income smokers, given the added burden of tax. ${ }^{92}$

An additional element is the notion of "social exchange" applied to tobacco policy, which proposes that justice and compassion would require that we use programmes and policy to replace tobacco use with something positive for vulnerable populations, such as women smokers. ${ }^{78}$ If these and related principles were the components of an ethical framework guiding the development of tobacco policies for low SES girls and women, consideration of the design and effects of tobacco control policies, on a group by group basis and with their involvement is required.

\section{Policy development}

Engage with girls and women of low SES to better tailor future policies to low income girls and women The processes of engagement must be respectful and can be built upon the traditions in community based research, action research and other collaborative community development work. Developing authentic partnerships with agencies, organisations, or individuals is critical and challenging, yet offers an opportunity to engage meaningfully with the groups most affected by the policy product. The processes of establishing the nature of the "unintended consequences" of policies are also critical and offer an opportunity for essential dialogue with low SES groups. This exploration will indicate an interest in knowing what repercussions emerge from imposing policies on low SES girls and women that are broad and blunt in their design and approach. ${ }^{93}$

Adopt a "rights" approach to policy development for low SES girls and women

Northridge suggests that US tobacco control policies should adopt a "health and human rights" framework to guide their future development (page 178). ${ }^{94}$ She posits that tobacco control policies can be built upon using this model to better serve the principles of social justice and to more closely meet the needs of vulnerable populations and argues for focused approaches in research and practice to address "the higher burden of tobacco use and exposure to environmental tobacco smoke among poor and working class populations" (page 179). ${ }^{94}$ Lambert further argues that international treaties such as the Framework convention on Tobacco Control (FCTC) and the Convention to Eliminate Discrimination Against Women (CEDAW) create legal bases for providing women specific and sensitive policies and programmes and gender specific protections and education about tobacco. ${ }^{95}$

\section{Research}

Develop participatory and collaborative research models to ensure that vulnerable communities are engaged in the research process

Research to support the development of comprehensive tobacco policy should include smokers in the research design. In particular, in trying to effect change among certain subpopulations where smoking prevalence is high and participation in research is infrequent, members of these communities (for example, low income women and girls, Aboriginal women, women experiencing violence) should be involved.

Refine existing measurement tools such that sex, gender, and diversity issues are taken into account This includes both the assessment of tobacco use as well as measures of inequality and/or disadvantage. Many tobacco use measures have not been validated on diverse populations. Accurate and appropriate tobacco use measures are needed for ethical research to ensure that the needs of diverse communities are heard and considered in policy development.

Although several health outcomes are used as "markers" of low SES (for example, low birthweight babies), few tools exist that measure disadvantage or discrimination directly. In their study of the health selection hypothesis (which suggests that people with good health at a young age will increase their SES, while the opposite is true for those with poor

\section{Policy implications}

This paper suggests changes to the process and content of tobacco policy development. It suggests using a gender and diversity based analysis in development and developing a framework for developing more sensitive and tailored programmes, policy, and research to address the needs of vulnerable girls and women who are affected by tobacco use. 
health), Hammarstrom and Janlert discuss the need for gender discrimination to be considered in research into social inequalities in health. ${ }^{96}$ Although many studies have examined this concept, Hammarstrom and Janlert point out that few have considered discrimination as mediating the experience. One example of a useful assessment tool is the recently developed Experiences of Discrimination (EOD) measure, ${ }^{97}$ a self report instrument that assesses exposure to racial discrimination. As the authors of the study point out, valid and reliable measures are needed in large scale population studies to better understand the link between discrimination and health outcomes, and thus to further action and change to social inequalities in health.

\section{Engage with research users to determine existing gaps in knowledge}

Sheldon notes the importance of evidence based policymaking, while also acknowledging the challenges of producing research findings that health care policymakers and managers can use. ${ }^{98}$ An ethical approach to tobacco policy must entail a reconsideration of research practices. Lavis et al carried out a knowledge synthesis project to identify ways to improve the utility of systematic reviews. ${ }^{99}$ There seemed to be consensus among health care managers and policymakers that researchers should highlight key findings relevant to decision making, provide sufficient information to contextualise the applicability of the findings to the community in question, and present consideration of both the benefits and risks of an intervention. They also call for systematic reviews that go beyond considering only published literature and incorporate other sources of knowledge.

\section{Programmes}

\section{Incorporate an ethical base into tobacco programmes and protocols}

Although outside the purview of this paper, certain policies that bear on the scope and ability of tobacco prevention and cessation programs are relevant to low SES girls and women. Health insurance coverage of cessation aids, disposition of tobacco tax monies, and funding of tailored programmes and protocols are but a few examples of areas in which policy may make a difference to the nature and effect of the programming. Following up on the notions of increasing the benefits to the group, and, if possible, offering some social exchange to those women who quit, challenges tobacco control advocates to embed something in return for giving up tobacco use. As a result, tobacco programming and ultimately tobacco control policy becomes a more generalised activity, delving into areas of social welfare, social support, economic renewal, education, and child and housing support. Fully embracing these agendas for low SES girls and women would show a concern with the general welfare of women and would reflect values in keeping with social justice.

\section{CONCLUSIONS AND RECOMMENDATIONS}

Firstly, including a GBA in all tobacco policy research is clearly overdue. Some countries recognise gender among the determinants of health and accordingly apply a sex, gender, and diversity analysis to explain and rectify differences that manifest in low SES girls' and women's tobacco use patterns. In many other countries, this is not yet the case. This approach has been used in specific situations and certain countries, but needs to become a global standard. Such an approach leads to the development and acceptance of tailored programmes as well as tailored policies, reflecting the specific conditions of tobacco use and responses to tobacco policy among low SES girls and women.

Secondly, more basic research is required to fully answer the question of the differential effect of tobacco policies on low SES girls and women. Key to this is the creation and provision of more precise data on the effects of policies on low SES girls and women. Other authors and organisations have called for better data, including the development of uniform measures, methodologies, and evaluations. ${ }^{81} 100$ Clearly, it is not sufficient to merely monitor the trends and rates by publishing sex disaggregated statistics categorised by SES measures, as new measures need to be developed in order to accurately assess aspects of disadvantage and gender as a determinant of health.

Thirdly, the tobacco control movement needs to reflect on a more comprehensive vision if it is to bring refreshed meaning to "comprehensive" tobacco policies. It needs to engage in wider economic and social policy development, addressing issues such as housing, access to childcare, and caregiving burdens for girls and women, along with traditional tobacco control policy. This is a broad shift, but one that can be matched by raising awareness and interest in tobacco use and policy among other sectors, such as social welfare, housing, correctional, antiviolence, or mental health services.

Finally, the most important element in encouraging a different approach is a political commitment to developing ethical, tailored policies that reflect social justice principles and are devoted to eroding inequalities of access to health. This framework assumes a values base reflecting shared concern about the welfare of low SES girls and women. Leaving behind the notion that the problem of tobacco use is an individual behaviour requiring modification is a key step in this process. It is essential to recognise that tobacco use is both a response to and a feature of, social and economic inequality and marginalisation and may bring solace and pleasure to lives where there may be little. Ensuring that tobacco policies affect low income girls and women in only positive ways will be a challenge, and will demand a reorientation of principles, a wider sense of duty, and a commitment to a wider social agenda.

\section{Authors' affiliations \\ L Greaves, N Jategaonkar, British Columbia Centre of Excellence for Women's Health, Canada}

Funding: the British Columbia Centre of Excellence for Women's Health is supported by Health Canada. Aspects of this work have been supported by the Canadian Tobacco Control Research Initiative and the Canadian Institutes for Health Research.

Conflicts of interest : none.

\section{REFERENCES}

1 Centers for Disease Control and Prevention. Health, United States, 2004. Hyattsville, MD: US Department of Health and Human Services, Centers for Disease Control and Prevention, National Center for Health Statistics, 2004, http://www.cdc.gov/nchs/data/hus/hus04trend.pdf\#topic.

2 Health Canada. The national strategy: moving forward. The 2003 progress report on tobacco control. Ottawa, ON: Ministry of Health, 2003.

3 Health Canada. Canadian tobacco use monitoring survey (CTUMS, 2004). Ottawa: Health Canada, Tobacco Control Program, 2004.

4 Lopez AD, Collishaw NE, Piha T. A descriptive model of the cigarette epidemic in developed countries. Tobacco Control 1994;3:242-7.

5 Daniel M, Cargo MD, Lifshay J, et al. Cigarette smoking, mental health and social support: data from a northwestern first nation. Can J Public Health 2004;95:45-9

6 Health Canada. 2000-2002 Report on tobacco control-update. Ottawa: Ministry of Health, 2002.

7 Briggs VL, Lindorff KJ, Ivers RG. Aboriginal and Torres Strait islander Australians and tobacco. Tob Control 2003;12(suppl 2):5-8.

8 Centers for Disease Control and Prevention. Cigarette Smoking Among Adults-United States, 2001. MMWR Morb Mortal Wkly Rep 2003;52:953-6.

9 Chollat-Traquet C. Women and tobacco. Geneva: World Health Organisation, 1992.

10 Fentiman IS, Allen DS, Hamed H. Smoking and prognosis in women with breast cancer. Int J Clin Pract 2005;59:1051-4.

11 Zhang B, Ferrence R, Cohen J, et al. Smoking cessation and lung cancer mortality in a cohort of middle-aged Canadian women. Ann Epidemiol 2005; 15:302-9. 
12 Varkey $\mathrm{AB}$. Chronic obstructive pulmonary disease in women: exploring gender differences. Curr Opin Pulm Med 2004;10:98-103.

13 Li YF, Langholz B, Salam MT, et al. Maternal and grandmaternal smoking patterns are associated with early childhood asthma. Chest 2005; 127:1232-41.

14 Hanke W, Sobala W, Kalinka J. Environmental tobacco smoke exposure among pregnant women: impact on fetal biometry at 20-24 weeks of gestation and newborn child's birth weight. Int Arch Occup Environ Health 2004:77:47-52.

15 Nelson E, Jodscheit K, Guo Y. Maternal passive smoking during pregnancy and fetal developmental toxicity. Part 1: gross morphological effects. Hum Exp Toxicol 1999; 18:252-6.

16 Nelson E, Jodscheit K, Guo Y. Maternal passive smoking during pregnancy and fetal developmental toxicity. Part 2: histological changes. Hum Exp Toxicol 1999; 18:257-64.

17 Ernster V, Kaufman N. Nichter M, et al. Women and tobacco: moving from policy to action, Bull World Health Organ 2000;78:891-901.

18 Centers for Disease Control and Prevention. Best practices for ccomprehensive tobacco control programs-August 1999. Atlanta: Centres for Disease Control and Prevention, 1999.

19 World Health Organisation. Guidelines for controlling and monitoring the tobacco epidemic. Geneva: WHO, 1998.

20 Health Canada. Canadian tobacco use monitoring survey (CTUMS): summary of results for 2003. Ottawa: Health Canada, Tobacco Control Program, 2003.

21 Wakefield M, Chaloupka F. Effectiveness of comprehensive tobacco control programmes in reducing teenage smoking in the USA. Tob Control 2000;9:177-86.

22 Pierce JP, Gilpin EA, Emery SL, et al. Has the California tobacco control program reduced smoking? JAMA 1998;280:893-9.

23 Kunst A, Giskes K, Mackenbach J. Socio-economic inequalities in smoking in the European Union. Applying an equity lens to tobacco control policies, For the EU Network on Interventions to Reduce Socio-economic Inequalities in Health. Rotterdam, Netherlands: Department of Public Health, Erasmus Medical Center, 2004, http://www.ensp.org/files/socio.pdf.

24 Graham H, Der G. Patterns and predictors of tobacco consumption among women. Health Educ Res 1999;14:611-18.

25 Lin CC, Rogot E, Johnson NJ, et al. A further study of life expectancy by socioeconomic factors in the national longitudinal mortality study. Ethn Dis 2003;13:240-7.

26 Pan American Health Organization. Fact sheet: gender equity in health Washington, DC: Pan American Health Organization, 2002.

27 Jacobsen B. The ladykillers: why smoking is a feminist issue. London: Pluto Press, 1981.

28 Jacobsen B. Beating the ladykillers. London: Pluto Press, 1986.

29 Greaves L. Smoke screen: women, smoking and social control. Halifax, UK: Scarlet Press, 1996.

30 Amos A, Haglund M. From social taboo to "torch of freedom": the marketing of cigarettes to women. Tob Control 2000;9:3-8.

31 Barbeau EM, Leavy-Sperounis A, Balbach, eds. Smoking, social class, and gender: What can public health learn from the tobacco industry about disparities in smoking? Tob Control 2004;13:115-20.

32 U. S. Department of Health and Human Services. Reducing tobacco use: a report of the surgeon general. Atlanta, GA: USDepartment of Health and Human Services, Centers for Disease Control and Prevention, Nationa Center for Chronic Disease Prevention and Health Promotion, Office on Smoking and Health, 2001.

33 World Health Organisation. Women and the tobacco epidemic; challenges for the 21 st century. Geneva: WHO, 2001.

34 Statistics Canada. National population health survey, 1996-97. Ottawa: Statistics Canada, 1999.

35 Cameron R, Wilson E. The summit challenge: introduction to the report of the Canadian tobacco control research summit. Ottawa, ON: April 2002, http:// www.ctcri.ca/files/intro_pres.pdf.

36 Public Health Agency of Canada. National population health survey highlights. Smoking behaviour of Canadians, Cycle 2, 1996/97 (January 1999, no 1). Ottawa: Public Health Agency of Canada, 1999, http:// www.hc-sc.gc.ca/pphb-dgspsp/ccdpc-cpcmc/cancer/publications/nphssboc/index_e.html.

37 ALA. Trends in tobacco use. USA: American Lung Association, 2004.

38 Reading J. The tobacco report, In:First nations and Invit regional health survey. Ottawa, ON: First Nations and Inuit Regional Health Survey National Steering Committee, 1999

39 Austin SB, Ziyadeh N, Fisher L, et al. Sexual orientation and tobacco use in a cohort study of US adolescent girls and boys. Arch Pediatr Adolesc Med 2004; 158:317-22.

40 Siahpush M, Borland R, Scollo M. Prevalence and socio-economic correlates of smoking among lone mothers in Australia. Aust N Z J Public Health 2002; $26: 132-5$

41 Siahpush $M$. Why is lone-motherhood so strongly associated with smoking? Aust N Z J Public Health 2004;28:37-42.

42 Nichols HB, Harlow BL. Childhood abuse and risk of smoking onset. $J$ Epidemiol Community Health 2004;58:402-6.

43 Graham H. Promoting health against inequality: using research to identify targets for intervention - a case study of women and smoking. Health Educ $J$ 1998;57:292-302.

44 Helmert U, Shea S, Bammann K. Social correlates of cigarette smoking cessation: findings from the 1995 microcensus survey in Germany. Rev Environ Health 1999; 14:239-49.

45 Kandel DB, Wu P, Davies M. Maternal smoking during pregnancy and smoking by adolescent daughters. Am J Public Health 1994;84:1407-13.
46 Niaura R, Bock B, Lloyd EE, et al. Maternal transmission of nicotine dependence: psychiatric, neurocognitive and prenatal factors. Am J Addict 2001;10:16-29.

47 Chassin L, Presson C, Rose J, et al. Parental smoking cessation and adolescent smoking. J Pediatr Psychol 2002;27:485-96.

48 Faucher MA. Factors that influence smoking in adolescent girls. Journal of Midwifery Women's Health 2003;48:199-205.

49 Greaves L, Johnson J, Bottorff J, et al. Reducing harm: a better practices review of tobacco policy and vulnerable populations. Vancouver, BC: BC Centre of Excellence for Women's Health, 2004

50 Greaves L, Johnson J, Bottorff J, et al. What are the effects of tobacco policies on vulnerable populations? A better practices review. Can J Public Health (in press).

51 Canadian Tobacco Control Research Initiative (CTCRI). Better solutions for complex problems: descriptions of a model to support better practices for health. Toronto: CTCRI, 2006. (http://www.ctcri-ca/files/ Better_practices book.pdf

52 Manske S, Maule C, O'Connor S, et al. A call for action to support best practices in evaluation of comprehensive tobacco control evaluation strategies. Chronic Dis Can 2003;24:32-7.

53 McDonald P, Colwell B, Backinger CL, et al. Better practices for youth tobacco cessation: evidence of review panel. Am J Health Behav 2004;27/suppl 2):S144-58.

54 Greaves L, Cormier R, Devries K, et al. Expecting to quit: a best practices review of smoking cessation interventions for pregnant and postpartum girls and women. Vancouver, BC: BC Centre of Excellence for Women's Health, 2003.

55 Miller SJ, Manske SR, Phaneuf MR, et al. Identifying best practices for group smoking cessation: comparing CCS fresh start to best practices. Waterloo, $\mathrm{ON}$ : Centre for Behavioural Research and Program Evaluation, University of Waterloo, 2001

56 Health Canada. Exploring concepts of gender and health. Ottawa: Health Canada, 2003.

57 Eichler M. Feminist methodology. Current Sociology 1997;45:9-36.

58 Hinds MW. Impact of a local ordinance banning tobacco sales to minors. Public Health Rep 1992;107:355-8.

59 Castrucci BC, Gerlach KK, Kaufman NJ, et al. Adolescents' acquisition of cigarettes through non-commercial sources. J Adolesc Health 2002;31:322-6.

60 Klonoff EA, Landrine H, Alcaraz R. An experimental analysis of sociocultural variables in sales of cigarettes to minors. Am J Public Health 1997;87:823-6.

61 Pearce D, Schwartz D, Greaves, L. No giff: tobacco policy and Aboriginal people in Canada. Vancouver, BC: British Columbia Centre of Excellence for Women's Health (in press).

62 Chaloupka FJ, Pacula RL. Sex and race differences in young people's responsiveness to price and tobacco control policies. Tob Control 1999;8:373-7.

63 Lewit EM, Hyland A, Kerrebrock N, et al. Price, public policy, and smoking in young people. Tob Control 1997;6(suppl 2):S17-24.

64 Biener L, Aseltine RH Jr, Cohen B, et al. Reactions of adult and teenaged smokers to the Massachusetts tobacco tax. Am J Public Health 1998;88:1389-91.

65 Gritz ER, Thompson B, Emmons K, et al. Gender differences among smokers and quitters in the working well trial. Prev Med 1998;27:553-61.

66 Farrelly MC, Evans WN, Sfekas AE. The impact of workplace smoking bans: results from a national survey. Tob Control 1999;8:272-7.

67 Proescholdbell RJ, Chassin L, MacKinnon DP. Home smoking restrictions and adolescent smoking. Nicotine and Tobacco Research 2000;2:159-67.

68 Wakefield MA, Chaloupka FJ, Kaufman NJ, et al. Effect of restrictions on smoking at home, at school, and in public places on teenage smoking: cross sectional study. BMJ 2000;321:333-7.

69 Leigh JP. Cigarette taxes-regressive or progressive? [Letter]. West J Med 1989;150:467

70 Greaves L, Ferrence R. A debate on tobacco taxation policy. Chronic Diseases in Canada 1992;13:58-60.

71 Remler DK. Poor smokers, poor quitters, and cigarette tax regressivity. Am J Public Health 2004:94:225-9.

72 Action on Smoking and Health. Her share of misfortune: women, smoking and low income. An expert report of the ASH working group on women and smoking. London: ASH, 1993.

73 Hamilton VH, Levinton C, St-Pierre Y, et al. The effect of tobacco tax cuts on cigarette smoking in Canada. CMAJ 1997;156:187-91.

74 Bayer R, Stuber J. Tobacco control, stigma, and public health: rethinking the relations. Am J Public Health 2006;96:47-50.

75 Lucas K, Lloyd B. Starting smoking: girls' explanation of the influence of peers. J Adolesc 1999;22:647-55.

76 Musher-Eizenman D, Holub S, Arnett M. Attitude and peer influences on adolescent substance use: the moderating effect of age, sex, and substance. J Drug Educ 2003;33:1-23.

77 Alesci N, Forster J, Blaine T. Smoking visibility, perceived acceptability, and frequency in various locations among youth and adults. Prev Med 2003;36:272.

78 Greaves L, Barr VJ. Filtered policy: women and tobacco in Canada. Vancouver, BC: BC Centre of Excellence for Women's Health, 2000.

79 Bottorff JL, Kalaw C, Johnson JL, et al. Couple dynamics during women's tobacco reduction in pregnancy and postpartum. Nicotine and Tobacco Research, (in press)

80 International Network of Women Against Tobacco-Europe. Report of INWAT Europe seminar on women and tobacco: part of the solution? Tobacco control policies and women. London, UK: Cancer Research Campaign, Health Development Agency, 1999.

81 European Communities. Tobacco or health in the European Union: past, present and future. Luxembourg: Office for Official Publications of the European Communities, 2004. 
82 Burns DM. Reducing tobacco use: What works in the population? J Dent Educ 2002;66:1051-60.

83 Warner KE. Tobacco control policy: from action to evidence and back again. Am J Prev Med 2001;20(supp 2):2-5.

84 Status of Women Canada. Setting the stage for the next century: the federal plan for gender equality. Ottawa: Status of Women Canada, 1995, http:// www.swc-cfc.gc.ca/pubs/066261951X/199508_066261951X_e.pdf.

85 Health Canada. Women's health strategy report. Ottawa: Health Canada, Bureau of Women's Health and Gender Analysis, 1999, http://www.hcsc.gc.ca/ahc-asc/pubs/strateg-women-femmes/strateg_e.html.

86 Health Canada. Exploring concepts of gender and health. Ottawa: Health Canada, 2003.

87 Tomlinson S. Towards a coordinated research agenda to reduce tobaccorelated problems in Canada: report on the Canadian tobacco control research summit 2002. http://www.ctcri.ca/en-pages/summitreport.htm (accessed 30 Apr 2003)

88 United States General Accounting Office. Women's health: NIH has increased its efforts to include women in research. Washington: United States General Accounting Office, Reports to Congressional Requesters, 2000.

89 Healton C, Nelson K. Reversal of misfortune: viewing tobacco as a social justice issue. Am J Public Health 2004;94:186-91.

90 Gray, N. The ethics of policies for the prevention of tobacco disease. Acta Oncol 2004;43:8-10.
91 Fox BJ, Cohen JE. Tobacco harm reduction: a call to address the ethical dilemmas. Nicotine and Tobacco Research 2002;4(suppl 2):S81-7.

92 Wilson N, Thomspon G. Tobacco taxation and public health: ethical problems, policy responses. Soc Sci Med 2005;61:649-59.

93 Wolfson M, Hourigan M. Unintended consequences and professional ethics: criminalization of alcohol and tobacco use by youth and young adults. Addiction 1997;92:1159-64.

94 Northridge ME. Building coalitions for tobacco control and prevention in the 21 st century. Am J Public Health 2004;94:178-80.

95 Lambert P. Health as a human right. In: Greaves L, Jategaonkar N, Sanchez S, eds. Turning a new leaf: women, tobacco and the future. Vancouver, BC: British Columbia Centre of Excellence for Women's Health, 2006

96 Hammarstorom A, Janlert U. Health selection in a 14-year follow-up study-a question of gendered discrimination? Soc Sci Med 2005;61:2221-32.

97 Krieger N, Smith K, Naishadham D, et al. Experiences of discrimination: validity and reliability of a self-report measure for population health research on racism and health. Soc Sci Med 2005;61:1576-96.

98 Sheldon TA. Making evidence synthesis more useful for management and policy-making. J Health Serv Res Policy 2005; 10(suppl 1):S1-5.

99 Lavis J, Davies H, Oxman S, et al. Towards systematic reviews that inform health care management and policy-making. J Health Serv Res Policy 2005; 10(suppl 1):S35-48.

100 Chollat-Traquet C. Evaluating tobacco control activities: experiences and guiding principles. Geneva: World Health Organisation, 1996. 